J. L. Scott, M. L.e Grossheck, and P. J. Mazzasz

Oak Ridge National Laboratory

P.0. Box X

Oak Ridge, Tennessee 37830

The $14-\mathrm{MeV}$ neutrons produced in a fusion reactor result in different Irradiation damage than the equivalent fluence in a fast breeded reactor, not only because of the higher defect generation rate, but because of the production of.significant concentrations of hellum and hydrogen. Although no fusion test reactor exists, the effects of combined displacement damage plus helium can be studied in mixed-spectrum fission reactors for alloys containing nickel (e.g., austenitic stainless steels). The presence of helium appears to modify vacancy and interstitial recombination such that microstructural development in alloys differs between the fusion and fission reactor environments.

Since mechanical properties of alloys are related to the miccostructure, the simultaneous production of heliur and displacement damage impact: upon key design properties such as tensile, fatigue, creep, and crack growth. Through an understanding of the basic phenomena occurring during irradiation and the relationships between microstructure and properties, alloys can be tailored to minimize radiation-induced swelling and improve mechanical properties in fusion reactor service.

\footnotetext{
${ }^{*}$ Research sponsored by Office of Fusion Energy, U.S. Department of
} Energy under contract W-7405-eng-26 with Union Carbide Corporation. 
Fusion power together with breeder reactors and solar energy is a candidate to solve mankind's long-term energy requirements. The raw materials for fusion power are deuterfum from water and lithium, which is used to produce tritiun, from slat deposits. Both are sufficiently abundant to provide for projected worldwide energy demands for centuries. The product of the fusion reaction is helium, a valuable resource. There will be neutron activation of the reactor structure during operation; but the exposed structure will decay to moderate levels of activity in a few decades, so that the waste problems of a fusion economy are small in comparison to those of fission reactors. Thus, if it can be made to work economically, fusion offers enormous benefit to mankind.

At present the primary obstacle to fusion power is plasma confinenent. Plasmas have been produced and confined, but not yet to the point of a self-sustained fusion process. A variety of confinement techniques are being explored, including tokamaks, tandem mirrors, and Inertial confinement systems. 1,2 It is likely that the Tokamak Fusion Test Reactor being built at Princeton will demonstrate energy breakeven before 1985. The feasibility of mirror reactors should be established soon thereafter. It will then remain to demonstrate the system that will lead to the most economical commercial power.

The materials demands for fusion reactors are severe. An idealized blanket and shield segment of a tokamak, shown in Figure 1, illustrates the functional requirements that materials must satisfy in a fusion power system. In this design, a niobium alloy is the structural material; and 
lithium is both a breeding material and coolant. Graphite is a neutron reflector and moderator. Water, and lead are both shielding materials. Directly outside the shield is the superconducting coll that provides the toroldal fleld. This coll consists of the superconductor Imbedded in a normal conductor. The temperatures at which the components operate in this design are indicated.

The blanket structure, coolant, breeding materlal, neutron moderator, and shielding. materials are common to all fusion devices. In a few designs, neutron-multiplication systems, are required for breeding. In magnetically confined systems, limiters Inside the first wall both intercept the plasma under off-normal condițions and protect the blanket. Inertially confined systems do not require limiters or superconducting magnets, but they have unique components such as powerful lasers or other Intense energy delivery systems, complex optical systems, and target pellets.

The first-wall structural material provides vacuum containment at $10^{-9}$ torr (130 nPa) before fueling, and also contains the breeding materlal, coolant, and reflector materials. It is desirable to operate at a reasonably high temperature $\left(>400^{\circ} \mathrm{C}\right)$ for good heat transfer and efficiency. Unless a protective coating is used, the wall material must be compatible with the plasma environment of photons, energetic ions, and neutral atoms. It must also be compatible with the coolant and breeding materials. That part of the structure that faces the plasma operates either in a high vacuum or in a hydrogenic environment at different stages of the burn. The external reactor structure may be exposed either to air, to an inert atmosphere, or to a vacuum. 
The harshest environmental condition faced by the first-wall structure is the intense radiation field:- Fusion reactions in a tokamak produce $3.5-\mathrm{MeV}(0.55-\mathrm{pJ})$ alpha particles, which heat the plasma, and 14.1-MeV (2.25-pJ) neutrons, which heat the blanket and breed tritium. Since the postively charged alpha particles and emitted in an intense magnetic field, their orbits are confined within the plasmá. After they heat ions and electrons within the plasma, their energy is transferred to the first wali primarily by bremstrahlung and line radiation. This heat flux, 0.2 to $0.8 \mathrm{mw} / \mathrm{m}^{2}$, is deposited on the first wall. In contrast, the neutrons have a mean free path of $0.3 \mathrm{~m}$ or more in the blanket, so that their energy is deposited throughout thi: blanket. The energy density of the neutron current through the first wall, called the "wall loading," is in the range 1 to $4 \mathrm{NW} / \mathrm{m}^{2}$, or 4.43 to $17.7 \times 10^{17}$ neutrons $/\left(\mathrm{m}^{2} \cdot \mathrm{s}\right)$. Scattering of these neutrons adds to the flux at the first wall, creating a total flux in the range 3 to $12 \times 10^{18}$ neutrons $/\left(\mathrm{m}^{2} \cdot \mathrm{s}\right)$. These fluxes are lower than the peak $f 1$ ux in a fast breeder reactor, about $5 \times 10^{18}$ neutrons $/\left(\mathrm{m}^{2} \cdot \mathrm{s}\right)$, but the neutrons are more energetic.

Two consequences stem from the high-energy neutrons. First, they displace atoms in the lattice. Secondly, inelastic collisions occur, to produce high helium and hydrogen concentrations within the lattice. Damage measures for type 316 stainless steel in a typical fusion reactor and in various available irradiation test facilities are compared in Table I. The helium production rate in a fusion reactor first wall made of stainless steel is at least 40 times that in a fast breeder reactor. As Table II shows, the extent of damage assessed by each index varies 
from metal to metal; but for all candidate materials for fusion reactors, the ratio of helium production to displacement per atom (dpa) production 1s much higher than it is in a fast reactor.

As the neutrons pass through the blanket and shield materials, atoms are knocked out of their equilibrium lattice sites, producing many vacancy-interstitial (Frenkel) pairs. Many defects are quickly annihilated, but some survive to interact with each other and with solute atoms to form dislocations and/or cavities, with affect the properties of the material. The effects are particularly important in the structural materials, which must perform well at the elevated temperatures and stresses required. The high concentrations of heliun, together with i: atomic displacements, often lead to swelling and degradation of mechanical properties, with the result that the life of the structure is considerably shortened. It is imperative that radiation effects be understood and materials optimized for fusion service if fusion power is to be economically feasible.

In this paper the present approach to the problems and the understanding of radiation damage in fusion systems will be discussed. Some of the basic processes taking place in the metal lattice will be described. Then, ways to optimize the alloys for improved ductility and reduced swelling are proposed.

\section{Approach to the Problem}

The alloys for fusion service are generally selected on the basis of reactor design studies. Some of the earliest reactor studies utilized very high temperatures; consequently, niobium and molybdenum alloys were the materials of choice. Other studies focused upon the use of existing 
commercial alloys, leading to the choice of austenitic stainless steels and nickel-base alloys. When emphasis was placed on the desire to minimize radioactive inventory, aluminum and vanadium alloys and SiC, were selected. Recently the potential advantages of ferritic stainless steels were recognized and they were added to the set of candidate alloys being studied for fusion. Titanium alloys have also been considered for fusion because of their many desirable properties. A comparison of varlous alloys for an important set of reactor performance criteria is given in Table III. The specific alloys now being studied are described in a recent review of alloy development for fusion. 3

The fact that no high flux fusion reactor test facility now exists : hinders alloy development for fusion. At'present, simulations must be used, requiring extrapolation to fusion reactor conditions. Various low-flux, 14-MeV facilities exist such as the Rotating Target Neutron Source (RTNS) at the Lawrence Livermore National Laboratory. These facilities permit the study of the evolution of the damage microstructure, and of properties sensitive to low fluences, but cannon produce fluences that match those of the fusion reactor environment. Fast-spectrum fission reactors can be used to evaluate the effects of displacenent damage alone. Irradiation with dual beams of heavy ions and helium in accelerators may permit study of the swelling behavior and the microstructural evolution of various alloys, but do not provide specimens for the effective evaluation of mechanical properties.

A high flux deuterium-lithium source, the Fusion Materials Irradiation Test Facility (FMIT), to be built in Richland, Washington, w111 be available in 1985. Its primary nission will be to verify methods 
developed to correlate the fusion environment with that in fission reactors. It will also be used, to generate design data on a few selected high-priority materials. In the 1990 s a fusion materials test reactor may be built.

Fortunately, a way exists to simulate the fusion reactor environment: nickel-containing alloys, such as autenitic stainless steels and nickelbase alloys, can yield helium by a two-step process to be discussed later.

In a mixed-spectrum fission reactor with both high-fast and highthermal neutron fluxes, fast neutrons produce the displacements, while thermal neutrons produce heliun. Typical facilities available for alloy development are the High Flux Isotope Reactor (HFIR) and the Oak Ridge Reseach Reactor (ORR). Since most of the' results to date have been obtained on the austenitic stainless steels, especially type 316 and modifications thereof, the remainder of the paper will focus on these alloys; however, many of the principles should apply to other alloy systems as we11.

\section{Basic Radiation Effects}

Before getting into the detailed behavior of austenitic stainless steels in the mixed-spectrum fission reactor tests, it is helpful to review the basic radiation effects. A schematic diagram of a neutron interacting with a metal lattice is shown in Figure 2. An energetic neutron enters the lattice from the left and interacts elastically with a lattice atom which then becomes a primary knock-on atom. The neutron continues along its deflected path and creates other primary knock-on atoms until it no longer has sufficient energy to displace an atom, or until it is absorbed by a nucleus, creating a transmutation product. The prinary 
knock-on atom at first loses much of its energy through interactions with electrons. Then, as its energyd decrecses, nuclear cross sections increase and the atom causes many atom displacements as it traverses the lattice, creating isolated vacancies and interstitial atoms, replacement collisions, and finally a depleted zone rich in vacancles surrounded by an excess of interstitial atoms at the end of its range. In austenitic stainless steels at room temperature or above, the interstitial atoms are very mobile; and most recombine with vacancies with no lasting effect. A few interstitials are attracted to dislocations, grain boundaries, and other sinks, leaving an excess of vacancies in the lattice. Interstitials may also cluster to form two-dimensional pl telets, called interstitial loops. Vacancies are less mobile than interstitials, but are observed to migrate at significant rates at temperatures above 0.3 of the absolute melting temperature. Like interstitials, vacancies may be annihilated at a variety of sinks such as dislocations, grain boundaries, and precipitates. Vasancies may also cluster and grow into cavities, causing swelling; or they may also form dislocation loops.

\section{Helium Effects}

The presence of helium in the lattice can modify the response of the naterial. Interstitial helium, like a self-interstitial atom, is highly mobile; but it is also insoluble. Therefore, helium is quickly trapped by vacancies, dislocations, and other sinks. Vacancies containing hellum atoms may be mobile. The exact mechanisms of notion are not known, but there is ample evidence that helium and vacancies flow in a coupled fashion at reactor damage rates $\left(10^{-6} \mathrm{dpa} / \mathrm{s}\right)$. Since vacancy clusters are stabilized by heliun, the formation of cavities nornally occurs much 
earlier in a fusion reactor than in a breeder reactor where little heliun is produced. Also the concentration_nf cavities is sometimes much higher in the case of the fusion reactor. The result is that swelling should begin eariier in a fusion reactor. The rate of swelling, however, is lower at high fluences in austenitic stainless steels, particularly when a high concentration of helfum-filled cavities acts as the dominant sinks for point defects in the systems.

High coneentrations of helium-filled cavities in che matrix have little effect on the properties of austenitic stainless steels at room temperature; but, at temperatures above $400-500^{\circ} \mathrm{C}$, helium can migrate and collect at the grain boundaries, seriouly reducing ductility and causing intergranular failure. Figure 3 shows a 'scanning electron micrograph of the fracture surface of annealed Inconel 600 irradiated in HFIR at $650^{\circ} \mathrm{C}$ to a fluence that produced 1780 at. ppm He in the structure. 4 The sample. fractured at room temperature in a brittle manner. So much belium accumulated at the grain boundaries that metallic bonding was provided only by thin webs (white in the photograph). One strategy for application of materials to fusion service is to design an alloy that reduces the heliun concentration at the grain boundaries.

\section{Effects of Helium on Mechanical Properties}

The effects of helium on mechanical properties can be studied by introduction of helium efther before or simultaneousiy with irradiation in much the same say that microstructural evolution is studied. The major difference lies in the fact that mechanical properties are largely bulk properties and must be studied with larger specimens than are used for electron microscopy. 
As was discussed earlier, helium formed from $(n, \alpha)$ reactions from fusion neutrons is an inescapable part of the fusion environment. The effects of helium can be studied by irradiation in 14-MeV-neutron accelerators, which better simulate the fusion environment than any other device currently available. However, this technique suffers from two serious disadvantages: the high-flux volume is so small that only a few specimens can be irradiated at a time, and the fluxes available are so low that the regine of helium embrittlement has not been attained. Even when a large high-flux neutron source becomes available (FMIT in 1985), the irradiation space will be so limited that only experiments that correlate 14-ileV-neutron effects with simulations will be performed. Simulation techniques that allow larger numbers of specimens to be studied will be necessary to develope the mechanical properties data base necessary for the design and construction of a fusion reactor.

Simulation Techniques. The techniques being used at the present time for fusion simulation may be grouped into two classes: those that introduce helium prior to irradiation and those that introduce helium simultaneously with irradiation. In the first category are the following: (1) accelerator implantation and (2) tritium trick doping. Methods introducing helium simultaneously with irradiation are: (1) dual-beam ion irradiation and (2) transmutation-produced helium from thermal neutrons in mixed-spectrum reactors.

Accelerator implantation consists of bombarding very thin $(-0.25 \mathrm{~mm})$ specimens with high-energy $\alpha$-particles in a manner that distributes the a-particles uniformly throughout the specimen thickness. Implantation can be followed by neutron irradiatici to complete the simulation of the 
fusion environment. This method has the advantage that it can be used with any alloy system. It suffers from the disadvantage that only thin specimens that are subject to extraneous surface effects and corrosion can be employed.

Tritium trick doping is a clever technique that takes advantage of the decay of tritiun to ${ }^{3}$ He with a 12 -year half-life. Tritium is introduced into the specimens by equilibration with a tritium atmosphere. The tritium is then allowed to decay long enough to produce the desired concentration of helium, and then the excess tritium is allowed to diffuse out. The method results in a uniform distribution of helium in large specimens but suffers from the disadvantage that it applies only to metals with high solubilites for hydrogen. This, limits the method to refractory metals such as niobium and vanadium and to titanium. Concentrations are limited by the decay time to tritium and the solubility.

Dual-beam ion irradiation employs a beam of heavy ions to produce atomic displacement damage and a beam of $\alpha$-particles to deposit helium. The helium implantation is similar to accelerator implantation previously described. The simultaneous ion bombardment provides rapid results with simultaneous helium and displacement damage in specimens of minimal radioacitivty. This method is useful for fundamental studies of helium effects, and can be used with any alloy system, but is not as close a simulation to the fusion environment as neutron irradiation.

Transmutation-produced heliun from thermal neutrons in mixed-spectrum reactors permits simultaneous helium formation and displacement damage production. The use of fission reactors permits large numbers of a largesize specimens to be irradiated and, therefore, lends itself to support 
the mechanical properties base of a large alloy development program. Only $59_{\mathrm{Ni}}$ has a sufficiently large cross section for thermal-neutron absorption to be of use in helium production. The transmutation begins with $58_{\mathrm{Ni}}$ $(n, \alpha){ }^{59} \mathrm{Ni}$ which is followed by ${ }^{59} \mathrm{Ni}(n, \alpha){ }^{56} \mathrm{Fe}$, with both reactions occurring with thermal neutrons. This method results in a homogeneous distribution of helium in any practical-size specimen (size limited only by reactor space and dissipation of nuclear heating). However, it can be used only with nickel-bearing alloys. Concentrations of several thousand parts-per-milition helium can be attained, thus permitting the effects of helium at fusion reactor first-wa11 exposures as high at $40-50 \mathrm{MWyr} / \mathrm{m}^{2}$. In fact, sich high concentrations rar be attained that the quality of the fusion environment simulation is in question for nickel-base alloys and even in stainless steels, because of too high a helium-to-displacement per atom ratio. To more properly simulate the fusion environment;, special techniques such as adjusting the ratis of fast-to-thermal neutrons (called spectral tailoring) are used to achieve the proper ratio of atomic displacments to helium concentration. Transmutation doping can, therefore, be used to study the effecto of end-of-life helium concentration and study the effects of a closer simulation to the fusion environment. It suffers from the disadvantages that only nicke1-bearing alloys may be studied and, as with any fission reactor irradiation, the fact that specimens are highly radioactive.

As can be concluded from the previous discussion, in order to engage in a compressive alloy development program encompassing several alloy classes, several methods of fusion irradiation simulation must be used. 
Moreover, all of these methods (even accelerator-based 14-MeV-neutron generators) are only simulations of fusion reactor service. Therefore, their results must ultimately be correlated with service in an actual fusion device.

Results of Fusion Simulations. Nickel ions accompanied by $\alpha$-particles in a dual-seam accelerator have been used to study the effects on microstructure of preinjected helfum as compared with continuously produced helium.5 Significant differences between preinjection and continuous injection were observed in stainless steels in both phase stability and cavity nucleation.

Preinjection resulted in a finer microstructure than.simultaneous injection; both dislocation loops and volds were smaller and more numerous. Although mechanical properties were not measured, a more refined microstructure such as results from preinjection is expected to cause higher strength accompanfed by lower ductility.

Preinjection of helium followed by neutron irradiation in EBR-II was studied in $\mathrm{V}-20 \% \mathrm{Ti}$ by Tanka, Bloom, and llorak. 6 They observed essentially no change fin strength in the range of $400-700^{\circ} \mathrm{C}$, but a substantial drop in ductility at temperatures above $600^{\circ} \mathrm{C}$ for 90 and 200 at. ppm He and intergranular fracture at $700^{\circ} \mathrm{C}$. Since comparison samples without helium injection do not indicate any significant loss of ductility, the observed loss of ductility is attributed to helium. However, the refined microstructure observed in stainless steel in ion irradiation studies does not appear to apply to $\mathbb{L}-20 \mathrm{~T} \mathrm{~T}$, since no change in strength was observed. The loss of ductility is then not attributed to linited plastic flow resulting from dislocation pinning, but rather from the helium. Had 
significant strengthening been observed, no conclusions about the effect of helium could have been drawr...It-aan, therefore, be seen that the results of preinjection experiments must be interpreted cautiously.

The method of tritium trick doping was used to investigate helium embrittlement in another vanadium alloy, $\mathrm{V}-15 \% \mathrm{Cr}-5 \% \mathrm{~T} 1$, by Mattas et a1.7 Yield strength was maffected by helium concentrations up to 35 at. ppm, but ultimate tensile strength and elongation were decreased by the presence of helium especially at $700^{\circ} \mathrm{C}$ and above. Also consistent with the work of Tanaka et al., helium led to a tendency for intergranular fracture.

lixed-spectrum fission reactor iripdations have yielded the largest amo:ut of data on helium effects. The trends of large reductions in ductility at high temperatures continues to hold for mixed-spectrum reactor irradiations. However, strength may be increased or decreased, depending upon temperature and tnitial microstructure. The effect is dramatic in Incone1 600, where ductility drops from $16 \%$ to less than 17 upon irradiation at $600^{\circ} \mathrm{C}$ and the fracture mode transforms from ductile rupture to intergranular. 8 Type AISI 316 stalnless stee ${ }^{9}$ is more resistant to hellum embrittlement but nonetineless exhibits very low ductility above $600^{\circ} \mathrm{C}$ after $40 \mathrm{dpa}$ and approximately 4000 at. ppo He. The trends in both annealed and 20\% cold-worked type 316 stainless steel have been sumarized by Bloom, 10 who characterized the irradiation by the helium-to-displacenent ratio. A high lle/dpa ratio is considered to te approxinately $60-80$ obtained in the HFIR, while the term "Low He/dpa" Implies a ratio less than 1, obtained in fast reactors. Figures 4 and 5 show both yield stress and total tensile elongation for annealed and $20 z$ cold-worked type 316 
stainless steel. The Increase In yleld strength saturates at about 10 dpa and decreases with increasing temperature for both high and low He/dpa values. Ductility is significantly lower for the case of the high he/dpa value. In the annealed condition, ductility remains low throughout the temperature range studied, whereas a continuous decrease in ductility with Increasing temperature is exhlbited by material in the cold-worked condition. For type 316 scainless steel in both annealed and cold-worked condition, yleld strength is lower for the high He/dpa value. Lower strength accompanied by lower ductility is characteristic of radiation and hellum embrittlement.

Fatigue will be a major consideration in fusion reactors that operate in a cyclic mode. Fatigue in type 316 stainless stee 1 in the 20\%-cold-worked condition has been irvestigated following irradiation in the HFIR to produce helium levels as high as about 1000 at. ppm and dfsplacement levels up to 15 dpa (ref. 11). For irradiation and test temperatures of $430^{\circ} \mathrm{C}$, a reduction in fatigue life by a factor of 3 to 10 was observed (Figure 6). However, at $550^{\circ} \mathrm{C}$, no significant effect of irradiation on low-cycle fatigue 31 fe was observed. At both temperatures, the irradiation reduced the strain-range level of the $10^{7}$-cycle endurance Iinte from 0.35 to $0.30 \%$. However, $0.30 \%$ is sufficlently high for the normal operation of all present conceptual designs for fusion reactors. Accident conditions must still be evaluated.

Various simulation techniques have been discussed, and sone results obtained with each wethod have been described. It remains to validate each of these techniques, even the mixed-spectrum reactor experinents and the 14-MeV-neutron accelerator experiments, the two closest sinulations of 
the fusion environment. A step in this direction has been taken by Vandervoort et al.,12 who compated-terisile properties of specinens irradiated in two types of neutron accelerators $[\operatorname{Be}(d, n)$ and $T(d, n)]$ and a fission reactor. As predicted, the high-energy neutrons from the accelerators had a larger effect on strength and ductility per unit fiuence. However, when expressed in terms of damage energy, the effects on mechanical properties were found to be equivalent. It should still be kept in mind that the: fluences in these experiments were too low to yield significant amounts of helium. For fluences producing appreciable helium, the helium is expected to dominate. By the time FMIT or a fusion test facility becomes available, perhaps the efficts of helium wili be sufficiently understood to make the outcome of verification experiments simply a necessary check.

\section{Techniques for Minimizing the Efrects of Helium}

The metallurgist has avallable a number of tricks to minimize the dejeterious effects of helium. One technique that works well in type 316 stainless steel is cold work. Cold work produces a high concentration of dislocations in the lattice that act as trapping sites for helium. Figure 7 shows a comparison of cold-worked and annealed steel irradiated at teriperatures in the range $450-500^{\circ} \mathrm{C}$ so as to produce $42-53$ dpa and 3000-3800 at. ppm He (ref. 13). In the cold-worked material, nunerous small cavities are observed with a total of 27 swelling. In annealed steel, there are fewer, larger cavities and a total of 97 swelling. Calculations show that the amount of helium present in the samples can be accounted for in both cases by assuning that the cavities are equilibrium heliun bubbles with internal pressure, $P$, given by 


$$
P=\frac{2 \gamma}{r},
$$

where $Y=$ surface tension of the metali and $r=$ bubble radius. Smaller cavities contain helium at a higher pressure and result in less swelling for a given heliun content.

The effect of temperature on the swelling rates of cold-worked and annealed type 316 stainless steel irradiated in HFIR is shown in Figure 8. From 375 to about $550^{\circ} \mathrm{C}$ the swelling of both cold-worked and annealed samples is fairly independent of temperature, but both showed significantly more swelling at $680^{\circ} \mathrm{C}$. At this temperature recovery of the coldworked microstructure occurs, so that annealed and cold-work samples behave about the same. Increase heliuit. in HFIR of ten causes earlier swelling than observed in the breeder reactor (EBB-II), but void swelling in EBR-II can be greater than bubble swelling in HFIR at higher fluences.14 Even though the swelling was about the same in cold-worked samples below $550^{\circ} \mathrm{C}$, the bubble concentrations and sizes were different, as Table IV shows.

The use of controlled precipitation in an alloy can be more effective than cold work in mitigating the effects of hellum. In austenitic stainless steels, titaniun monocarbide (TiC) has been found to be an effective trap for hellum.15 Since the TiC is also rich in molybdenum, vanadium, and nioblum, it is usually referred to as metal monocarbide (MC). Figure 9 shows a micrograph of solution-annealed type 316 stainless steel with 0.23 wt $\% \mathrm{TI}$ after irradiation in $\mathrm{HFIR}$ at $600^{\circ} \mathrm{C}$ co $30 \mathrm{dpa}$ and 1850 at. ppm He. Although the MC phase is heavily decorated with helium, the Laves phase, a nornal precipitate in type 316 stainless steel, is free of 
helium. In ordinary cype 316 stainless steel, the Laves phase is an effective trap for helium as Figure-1C shows; but the bubble size is larger.

The primary reason the MC phase attracts helium migrating in vacancies is that it is an oversize misfit phase, having about a $70 \%$ increasse in atomic volume compared with untransformed austenite. Helium-laden vacancles are preferentially attracted by the large compressive stress around the MC.particles. In addition, $M C$ is much finer than the other precipitate phases, like Laves, reducing the migration distance. The overall result is that swelling is reduced and heliun is kept out of grain boundaries.

Disc ussion

The presence of helium formed by nuclear reactions in alloys during irradiations in the fusion environment can have serious consequences and must be taken into consideration. Tectsilques that can be used (and 11lustrated with austenitic stainless steel in this paper) including coldworking and controlled precipitation of phases that act as heliun traps. The same techniques can be used in other alloys, but the specific methods will vary for each alloy system. For all systems grain growth after helfum accumulation must be avoided. There will also be a fluence limit beyond which the helium effects are expected to become overriding in any alloy system. Nevertheless, optimized alloys will extend the lifetime of fusion reactors, considerably, with large economic benefits.

There is, at present, a large alloy deveiopment progran for fusion that was recently described elsewhere. 3 Many years of experimental and theoretical work will be required to fully understand the effects of 
displacement damage alone and the combined effects of helium and displacment damage on the behavior of materials. Once the materials are understood, optimized alloys can then be developed. There will remain a large testing program to generate the full data base required for engineering design and code qualification. Although our present knowledge is meager, there is every reason to be optimistic that good alloys for fusion service can be developed.

\section{References}

1. C. C. Baker, G. A. Carlson, and R. A. Krakowski, "Trends and Developments in Magnetic Confinement Fusiọn Reactor Concepts," Nucl Technol./ Fusion 1(1): 5-78 (January 1981). :

2. M. J. Monsler, J. Hovingh, D. L. Cook, T. G. Frank, and G. A. Moses, "An Overview of Inertial Fusion Reactor Design," Nucl. Technol./Fusion $1(3): \quad 302-58$ (July 1981).

3. R. E. Gold, E. E. Bloom, F. W. Clinard, Jr., D. L. Smith, R. D. Stevenson, and W. G. Wolfer, "Materials Technology for Fusion: Current Status and Future Requirements," Nucl. Technol./Fusion 1(2): 169-251 (Apri1 1981).

4. J. L. Scott, "The Development of Advanced Structural Materials for Fusion Power," pp. 330-39 In The 1980's - Payoff Decade For Advanced Materials, Vol. 25, Society for the Advancement of Materials and Process Engineering, Azusa, Calif, 1980.

5. N. H. Packan and K. Farre11, "Simulation of First Wall Damage," $J$. Nucl. Nater. $85 \& 86: 677-81$ (December 1979). 
6. 11. P. Tanaka, E. E. Bloom, and J. A. Horak, "Tensile Properties and Microstructure of Helium Injected and Reactor Irradiated V-20 Ti," To be published in the proceedings of the Second Topical Meeting on Fusion Reactor laterials, ANS, Seattle, Washington, August 7-10, 1981.

7. R. F. Mattas, H. Wiedersich, D. G. Atteridge, A. B. Johnson, and J. R. Remark, "Elevated-Temperature Tensile Properties of V-15 Cr-5 Ti Containing Helfum Introduced by Ion Bombardment and Tritiun Decay," pp. 199-208 in Proceedings of The Second Topical Meeting on The Technology of Controlted Nuclear Fusion CONF-760935-P1, 1976.

8. F. W. Hiffen, "Response of Inconel 600 to Simulated Fusion Reactor Irradiation," pp. 88-106 Effects of Radiation on Stmuctural Materials ASTM STP 683: American Soclety for Testing and Materials, Philadelphia, 1979.

9. E. E. Bloom and F. W. Hiffen, "The Effects of large Concentrations of Helium on The Mechanical Properties of Neutron-Irradiated Stainless Stee1,"J. Nucl. Mater. 58(2): 171-84 (1975).

10. E. E. Bloom, "Mechanical Properties of Materials in Fusion Reactor First Wall and Blanket Systems," J. Nucl. Mater. $85 \& 86: 794-804$ (December 1979).

11. M. L. Grossbeck and K. C. Liu, "Fatigue Behavior of Type 316 Stainless Steel Following Neutron-Irradiation-Inducing Helium," (Sumary) Trans. Am. Nucl. Soc. 34 (TANSAO 34): 186-88 (1980).

12. R. R. Vandervoort, E. L. Raymond, and C. J. Echer, "High-Energy Neutron Irradiation Effects on The Tensile Properties and Microstructure of 316 Stainless Stee1," Radiat. Eff. 45: 191-98 (1980). 
13. F. W. Wiffen, P. J. Maziasz, E. E. Bloom, J. O. Stiegler, and M. L. Grossbeck, "The Behaviōor of Type 316 Stainless Stzel Under Simulated Fusion Reactor Irradiation," pp. 146-59 in The Metal Science of Stainless Steels, The Metallurgical Society of AIME, Warrendale, Pa., 1978.

14. P. J. Maziasz, "Microstructural Development and Effects of Helium in Type 316 Stainless Steel Irradiated in HFIR and in EBR-II," ADIP Quart. Frog. Rep. March 31, 1981, DOE Report DOE/ER-0045/6, pp. 70-92.

15. P. J. Maziasz, "Helium Trapping and Ti-Rich MC Particles in NeutronIrradiated Type 316 + Ti Stánless Steels," Scr. Metalz. 14(11): $1251-56$ (1980). 


\section{List of Figures}

Fig. 1. Schematic diagram of

Fig. 2. Schematic diagram of neutron interactions with a metal

\section{lattice.}

Fig. 3. Inconel 600 , exposed in HFIR Reactor at $650^{\circ} \mathrm{C}$ to 8.5 displacements-per-atom level and 1780 at. ppm, fractured at $35^{\circ} \mathrm{C}$.

Fig. 4. Tensile properties of $20 \%$ cold worked type 316 stainless $\therefore$

steel. Open symbols for unirradiated samples, filled symbols for HFIR irradiated samples $\left(7.1\right.$ to $8.7 \times 10^{26}$ neutron $\left./ \mathrm{m}^{2}\right)$ and EBR-II trend curves for fluences 1.2 to $2.9 \times 10^{26}$ neutron $/ \mathrm{m}^{2}$.

Fig. 5. Tensile properties of solution annealed type 316 stainless stee1. Open symbols for unirradiated samples, filled symbols for HFIR irradiated samples $\left(5.6\right.$ to $8.7 \times 10^{26}$ neutron $\left./ \mathrm{m}^{2}\right)$ and EBR-II trend curves for fluences 1.2 to $2.9 \times 10^{26}$ neutron $/ \mathrm{m}^{2}$.

Fig. 6. Fatigue life of $20 \%$ cold worked type 316 stainless steel irradiated in UFIR at $430^{\circ} \mathrm{C}$ and tested at irradiation temperature (200-1,000 at ppm He, 5-15 dpa).

Fig. 7. Cold work reduces cavity size and swelling for irradiation In HFIR to high helium levels.

Fig. 8. A high helium content in type 316 stainless steel causes a high swelling rate.

Fig. 9. Solution-annealed type 316 stainless stcel with 0.23 wt $Z$ Ti after irradiation in HFIR at $600^{\circ} \mathrm{C}$ to $30 \mathrm{dpa}$ and 1850 at. ppm He.

Fig. 10. Helium trapping at a TiC particle in type 316 stainless steel. 
Fig. 11. Annealed type 316 stainless steel after irradiation in HFIR at $600^{\circ} \mathrm{C}$ to $30 \mathrm{dpa}$ and 1850 at $\mathrm{ppm}$. Hc. 
$300^{\circ} \mathrm{K}$

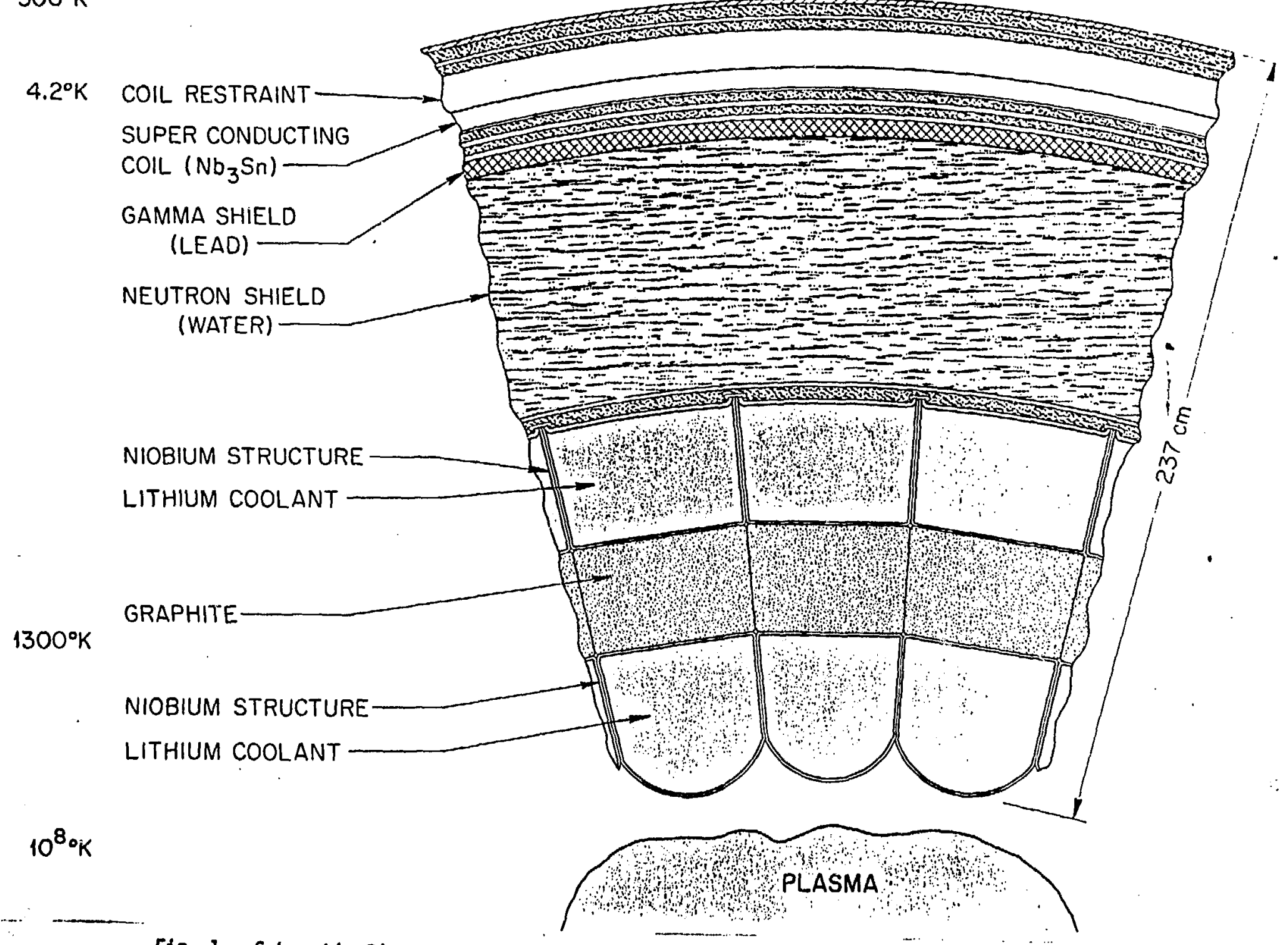

Fiq. 1. Schematic Diagram of Neutron Interacting with Metal Lattice. 


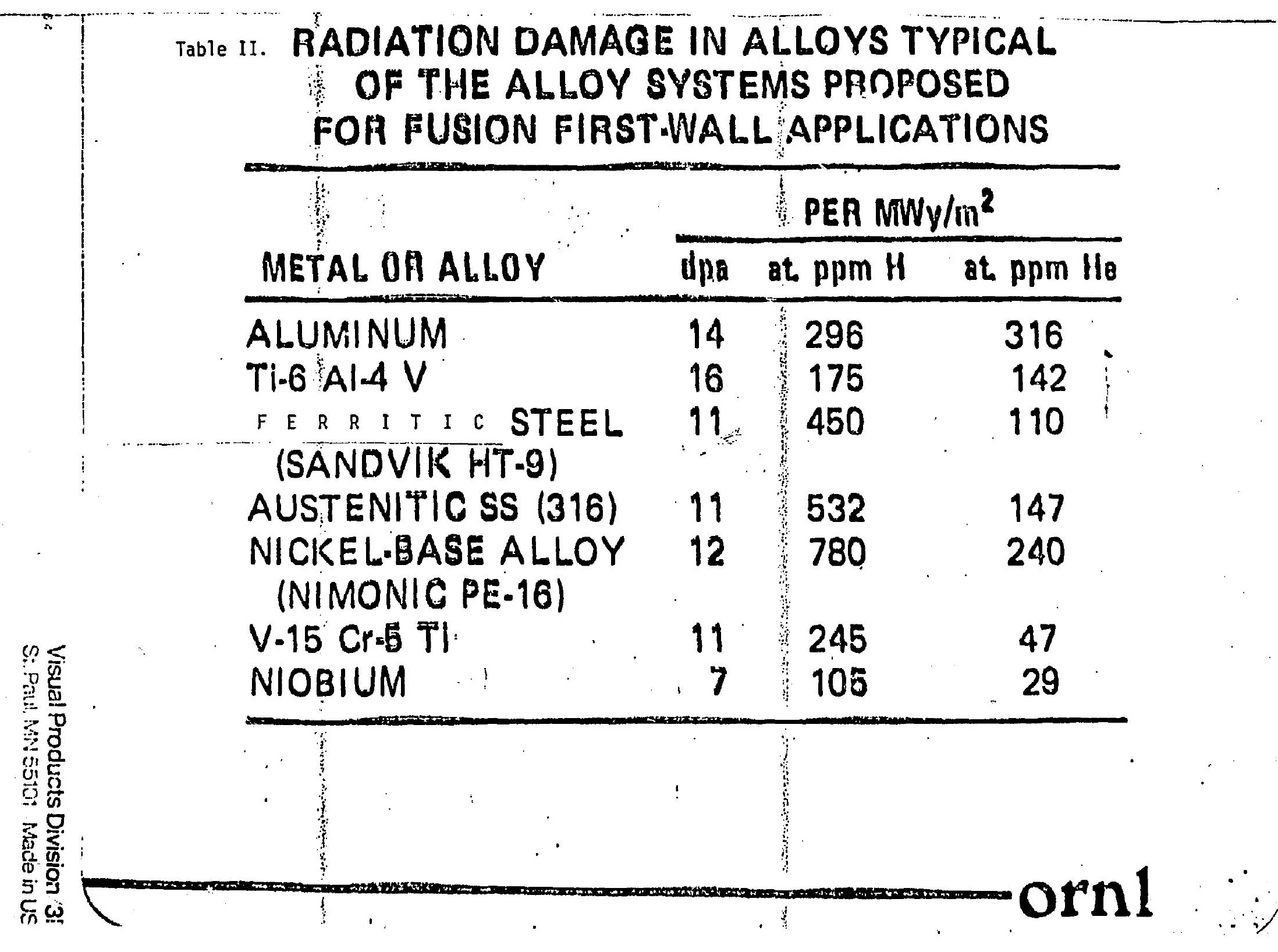


DRAFT 4

Table III. Comparison of candidate first-wall structural materials

\begin{tabular}{|c|c|c|c|c|c|c|c|c|}
\hline Requirement & $\begin{array}{c}\text { Austenitic } \\
\text { stainless } \\
\text { steels } \\
\end{array}$ & $\begin{array}{c}\text { Ferritic } \\
\text { steels }\end{array}$ & $\begin{array}{l}\text { High-nickel } \\
\text { alloys }\end{array}$ & $\begin{array}{c}\mathrm{Cb} \\
(\mathrm{Nb})\end{array}$ & $v$ & Mo & Ti & Al \\
\hline Availability and cost & $E$ & $E$ & G & $\mathbf{F}$ & $\mathbf{P}$ & $F$ & $E$ & $E$ \\
\hline Fabricability and weldability & $E$ & $\mathbf{G}$ & $E$ & $F$ & $F$ & $P$ & G & $E$ \\
\hline \multicolumn{9}{|l|}{ High-temperature mechanical } \\
\hline pruperties & $\mathbf{E}$ & $E$ & $E$ & $\mathbf{E}$ & $E$ & $\mathbf{E}$ & G & $P$ \\
\hline Thermal-stress resistance & $F$ & $\mathbf{E}$ & $F$ & $\mathbf{E}$ & $E$ & $E$ & G & $E$ \\
\hline \multicolumn{9}{|l|}{ Compatibility with: } \\
\hline Lithium & $\mathbf{G}$ & $\mathbf{G}$ & $\mathbf{P}$ & $E$ & $E$ & $E$ & $E$ & $P$ \\
\hline Hydrogen & $\mathbf{E}$ & $F$ & $\mathbf{E}$ & $\mathbf{F}$ & $F$ & $E$ & $\mathbf{P}$ & G \\
\hline Fused salts & $\mathbf{G}$ & G & $E$ & $\mathbf{P}$ & $\mathbf{P}$ & G & $\mathbf{P}$ & $P$ \\
\hline Helium (realistic purity) & $E$ & $E$. & $E$ & $\mathbf{P}$ & $\mathbf{P}$ & $\mathbf{G}$ & G & $\mathbf{E}$ \\
\hline Steam & $E$ & G & $E=$ & $\mathbf{P}$ & $\mathbf{P}$ & $\mathbf{P}$ & $E$ & G \\
\hline Sodium or potassium & E & $\mathbf{E}$ & $\mathbf{F}$ & $E$ & $F$ & E & $E$ & $P$ \\
\hline Air & E & G & $\mathbf{E}$ & $\mathbf{P}$ & $P$ & $\mathbf{P}$ & G & $E$ \\
\hline Low tritium permeability & $\mathbf{G}$ & $\mathbf{F}$ & $\mathbf{G}$ & $\mathbf{P}$ & $\mathbf{P}$ & $\mathbf{E}$ & $\mathbf{P}$ & G \\
\hline Low neutron activation & $\mathbf{P}$ & $\mathrm{F}$ & $\mathbf{P}$ & $\mathbf{p}$ & $E$ & $\mathbf{P}$ & $\mathbf{G}$ & $\mathbf{E}$ \\
\hline
\end{tabular}

Note. $E$, excellent; $G$, good; F, fair; and $P$, poor. 
ORN:L-DWG 74-11S10

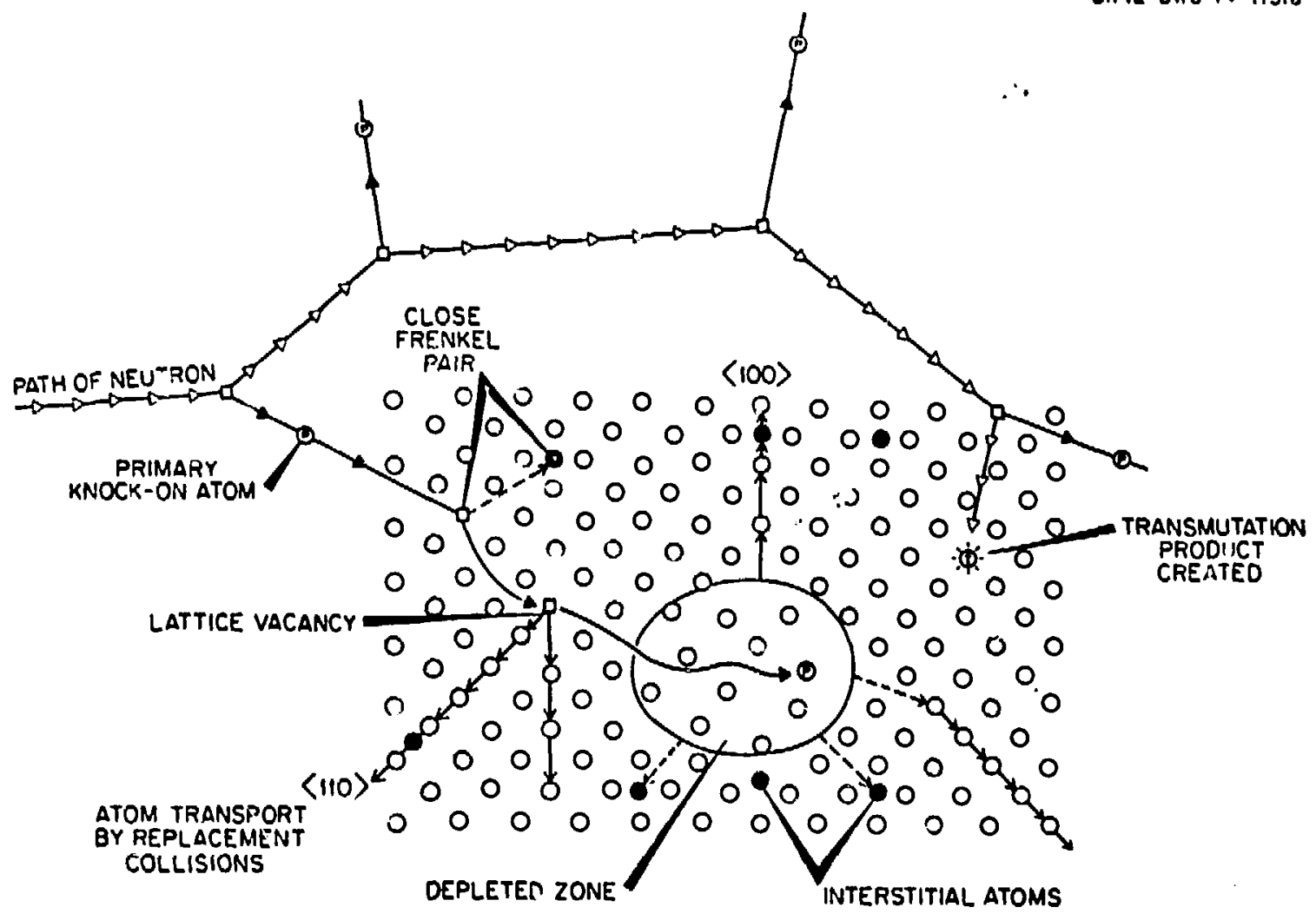

Fig. 2. Schematic diagram of neutron interactions with a metal lattice. 
Fig. 3. INCONEL 600, EXPOSED IN HFIR REACTOR AT $650^{\circ} \mathrm{C}$ TO 8.5 DISPLACEMENTSPER-ATOR LEVEL AND 1780 ATOM PARTS PER MILLION, FPACTURED AT $355^{\circ}=0$
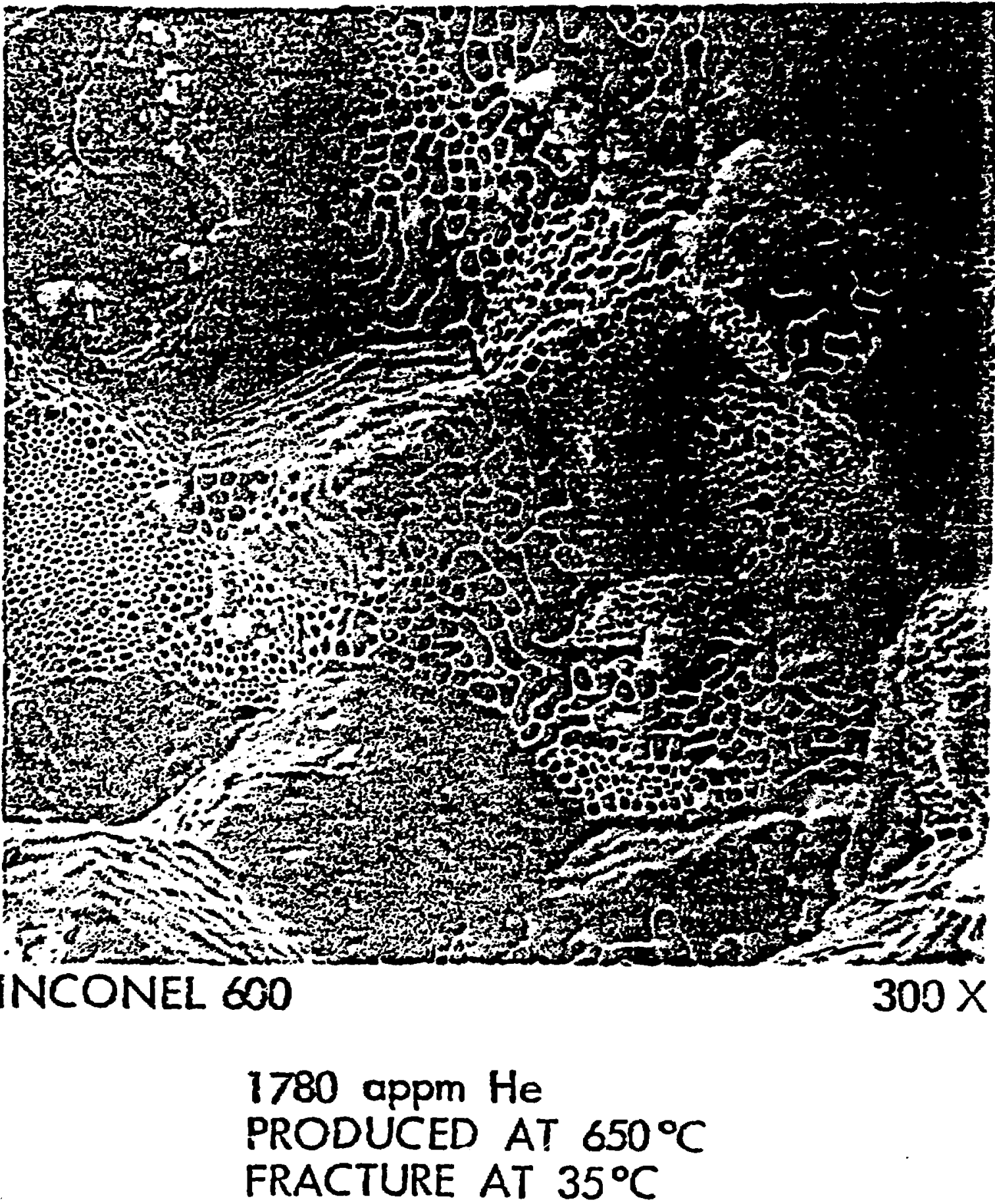
ORNL-DWG 74-12580

- YIELD STRESS

$\Delta \Delta$ ULTIMATE TENSILE STRESS
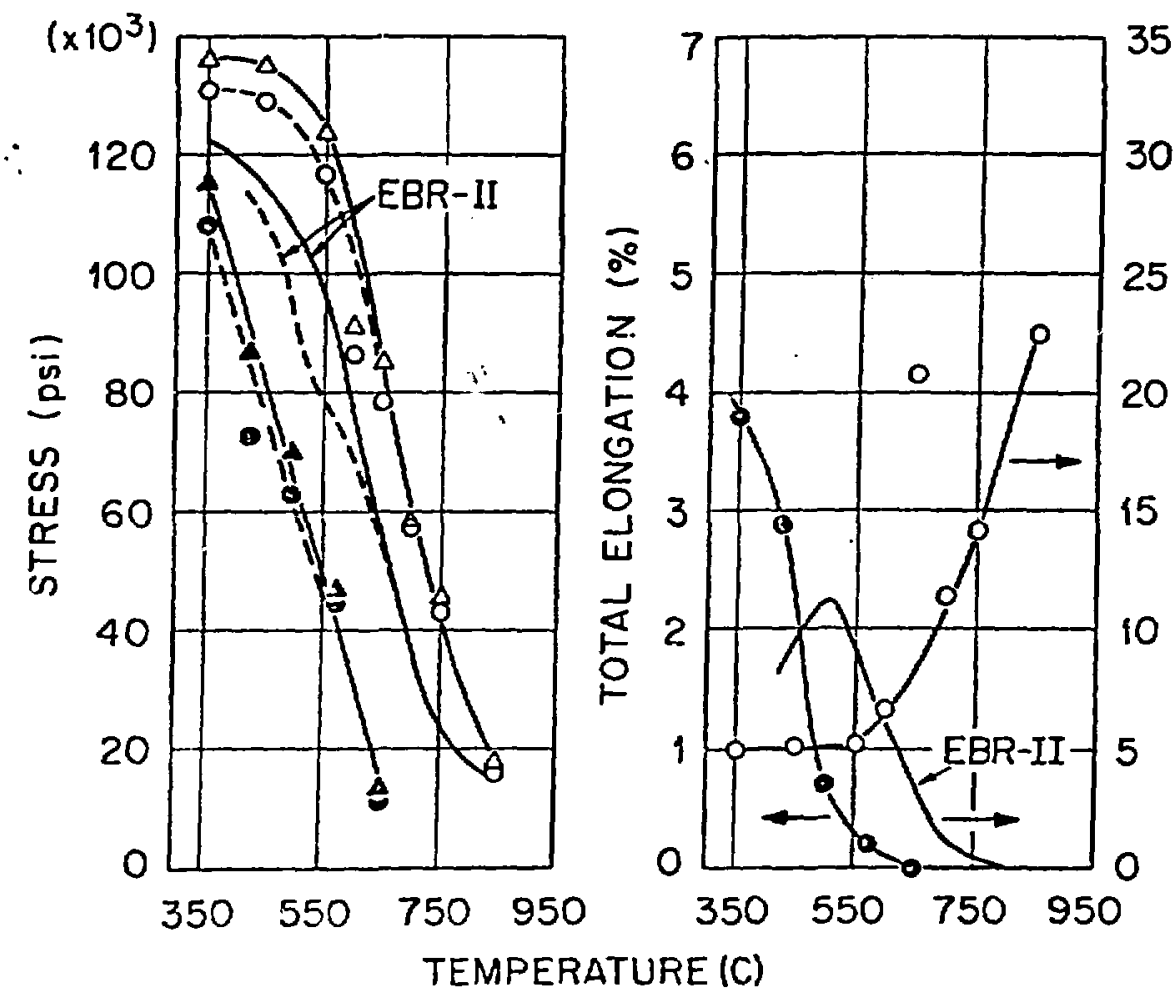

Fig. 4. Tensile Properties of $20 \%$ Cold Worked Type 316 Stainless Steel. Open Symbols for Unirradiated Samples, Filled Symbols for HFIR Irradiated Samples $\left(7.1\right.$ to $\left.8.7 \times 10^{26} \mathrm{n} / \mathrm{m}^{2}\right)$ and EBR-II Trend Curves for Fluences 1.2 to $2.9 \times 10^{26} \mathrm{n} / \mathrm{m}^{2}$. 
ORNL-DWG 74-12581

- YIELD STRESS

$\triangle \wedge$ ULTIMATE TENSILE STRESS

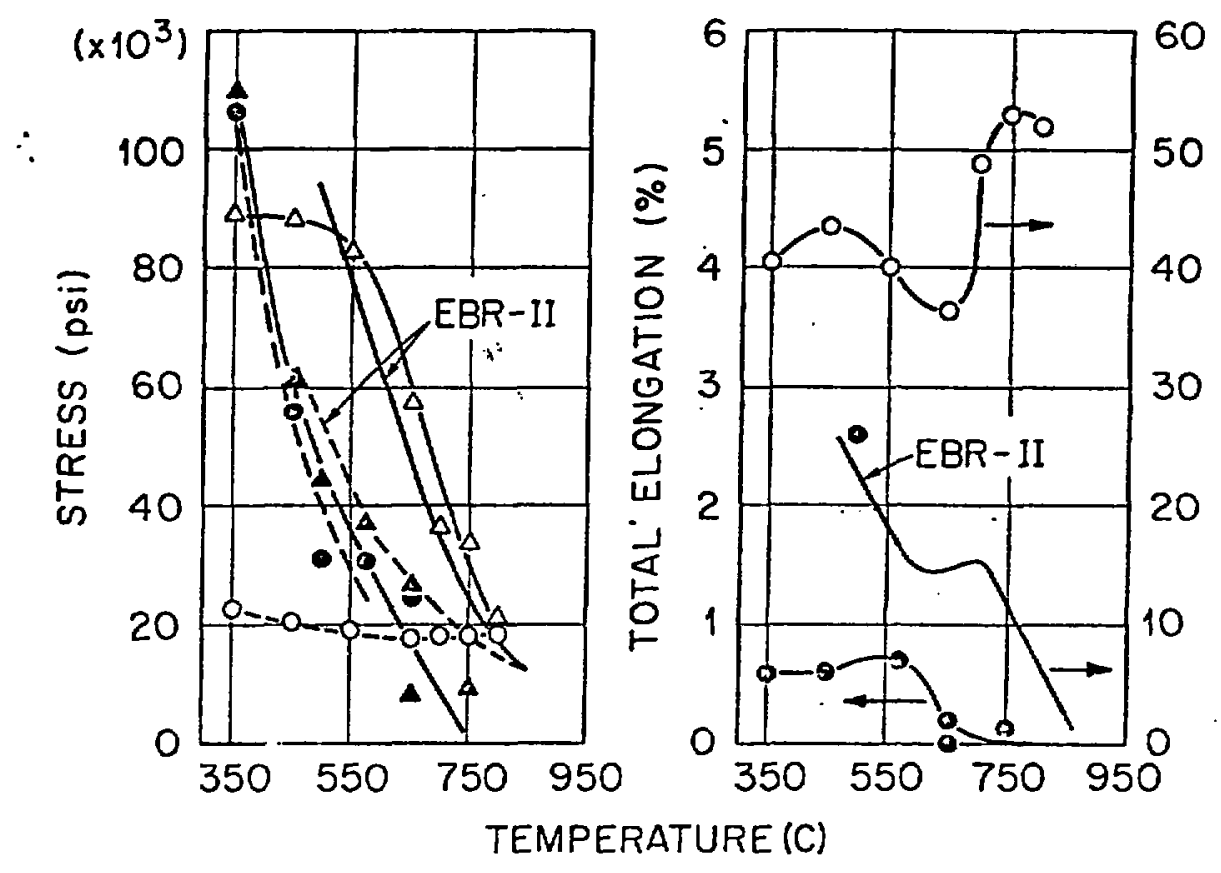

Fig. 5. Tensile Properties of Solution Annealed Type 316 Stainless Steel. Open Symbols for Unirradiated Samples, Filled Symbols for HFIR Irradiated Samples $\left(5.6\right.$ to $\left.8.7 \times 10^{26} \mathrm{n} / \mathrm{m}^{2}\right)$ and EBR-II Trend Curves for Fluences 1.2 to $2.9 \times 10^{26} \mathrm{n} / \mathrm{m}^{2}$. 


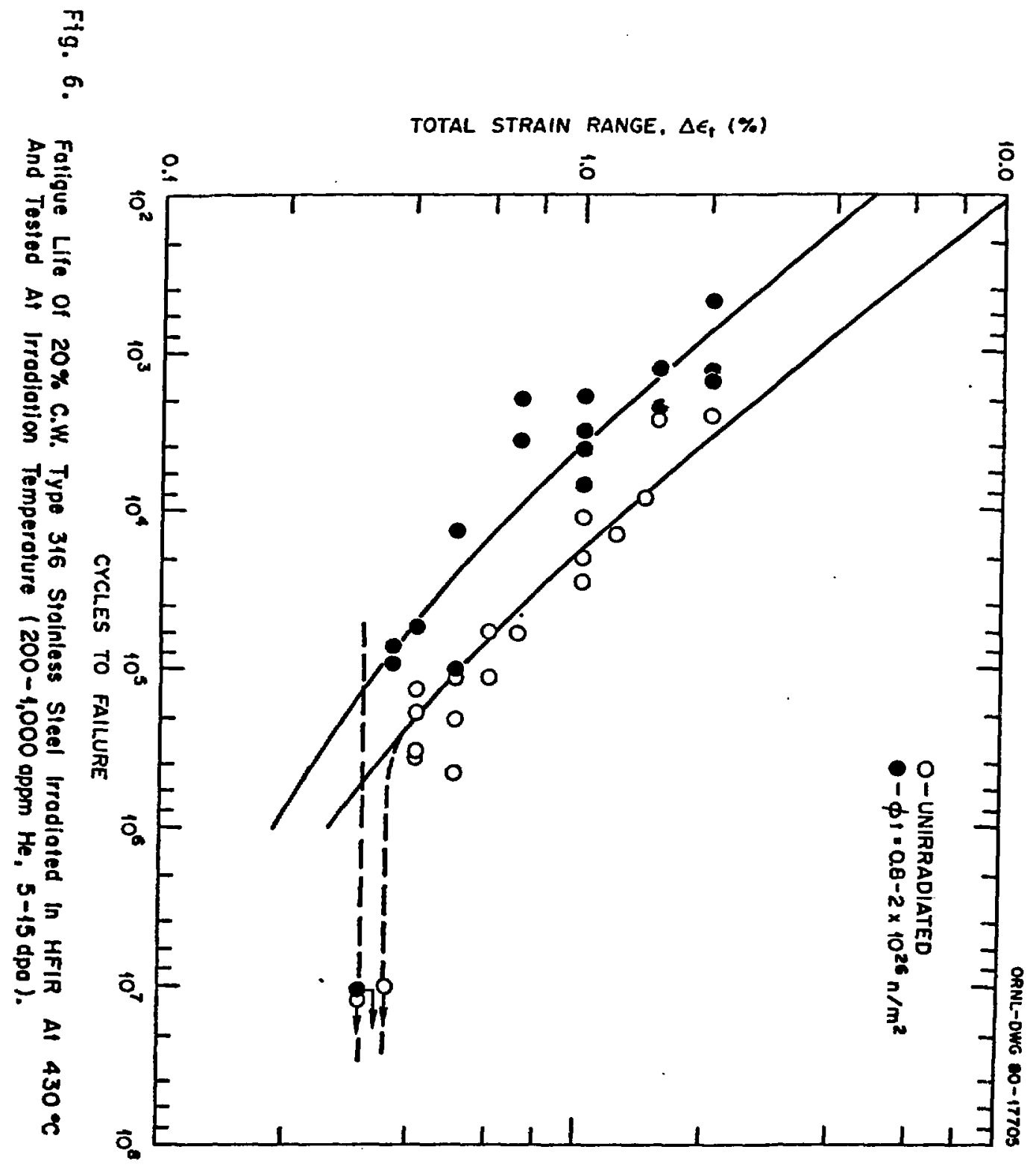


THE EFFECT OF COLD WORK

316 Stainless Steel

HFIR Irradiation
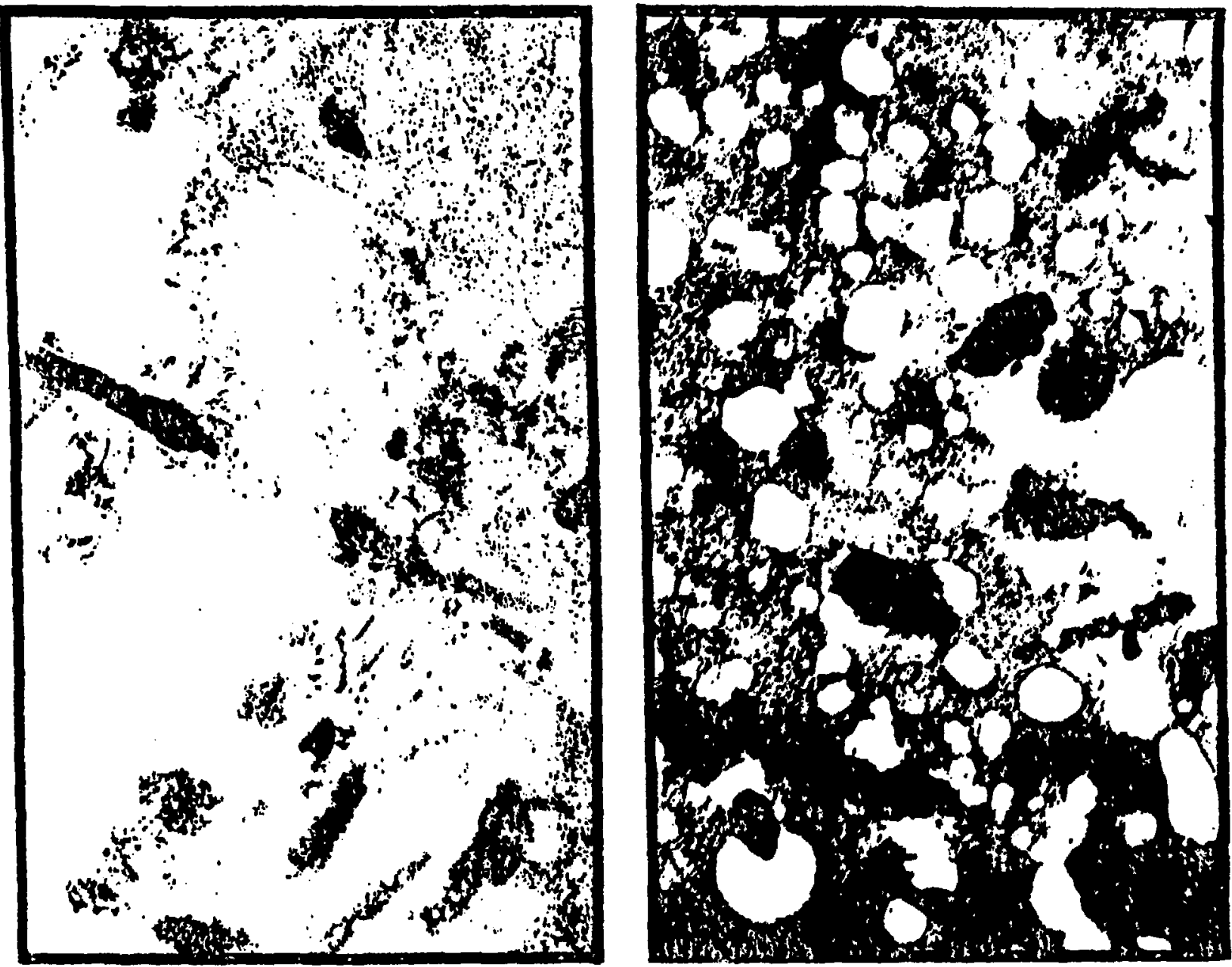

- $20 \%$ C.W. 31655

- Irrodiated at $450^{\circ} \mathrm{C}, 3800 \mathrm{appm}$ He, $53 \mathrm{dpa}$

- Swelling - 2.0\%

\section{- Annealed 316 SS}

- Irradiated at $480^{\circ} \mathrm{C}, 3000 \mathrm{apm} \mathrm{He}, 42 \mathrm{dpa}$ - Swelling - 9.0\%

\section{$0.1 \mu \mathrm{m}$}

Fig. 7. Cold Work Reduces Cavity Size and Swelling for Irradiation in HFIR to High Helium Levels. 
Table IV. Microstructural swelling data on irradiated type 316 stainless steels

\begin{tabular}{|c|c|c|c|c|c|c|}
\hline Condition & $\begin{array}{l}\text { Irradiation } \\
\text { temperature } \\
\left({ }^{\circ} \mathrm{C}\right)\end{array}$ & $\begin{array}{l}\text { Displacement } \\
\text { damage } \\
\text { (dpa)a }\end{array}$ & $\begin{array}{l}\text { Helium } \\
\text { content } \\
\text { (appm)b }\end{array}$ & $\begin{array}{c}\text { Swell ling } \\
(\%)\end{array}$ & $\begin{array}{l}\text { Cavity con- } \\
\text { centration } \\
\left.\text { (No. } / \mathrm{cm}^{3}\right)\end{array}$ & $\begin{array}{l}\text { Diameter } \\
(\AA)\end{array}$ \\
\hline \multirow[t]{5}{*}{$20 \%$ cold-worked } & 380 & 49 & 3320 & 2.2 & $1.8 \times 10^{16}$ & 95 \\
\hline & 450 & 54 & 3660 & 2.0 & $6.6 \times 10^{15}$ & 170 \\
\hline & 550 & 42 & 2990 & 1.4 & $2.4 \times 10^{15}$ & 210 \\
\hline & 600 & 60 & 4070 & 5.0 & $3.3 \times 10^{14}$ & 647 \\
\hline & 680 & 61 & 4140 & 16.8 & $6.3 \times 10^{13}$ & 1100 \\
\hline \multirow[t]{3}{*}{ Annealed } & 480 & 42 & 2950 & 8.8 & $1.4 \times 10^{15}$ & 386 \\
\hline & 550 & 42 & 2990 & 8.5 & $4.4 \times 10^{15}$ & 500 \\
\hline & 680 & 61 & 4740 & 15.2 & $4.6 \times 10^{13}$ & 1083 \\
\hline
\end{tabular}

${ }^{a}$ Displacements per atom.

batom parts per million. 


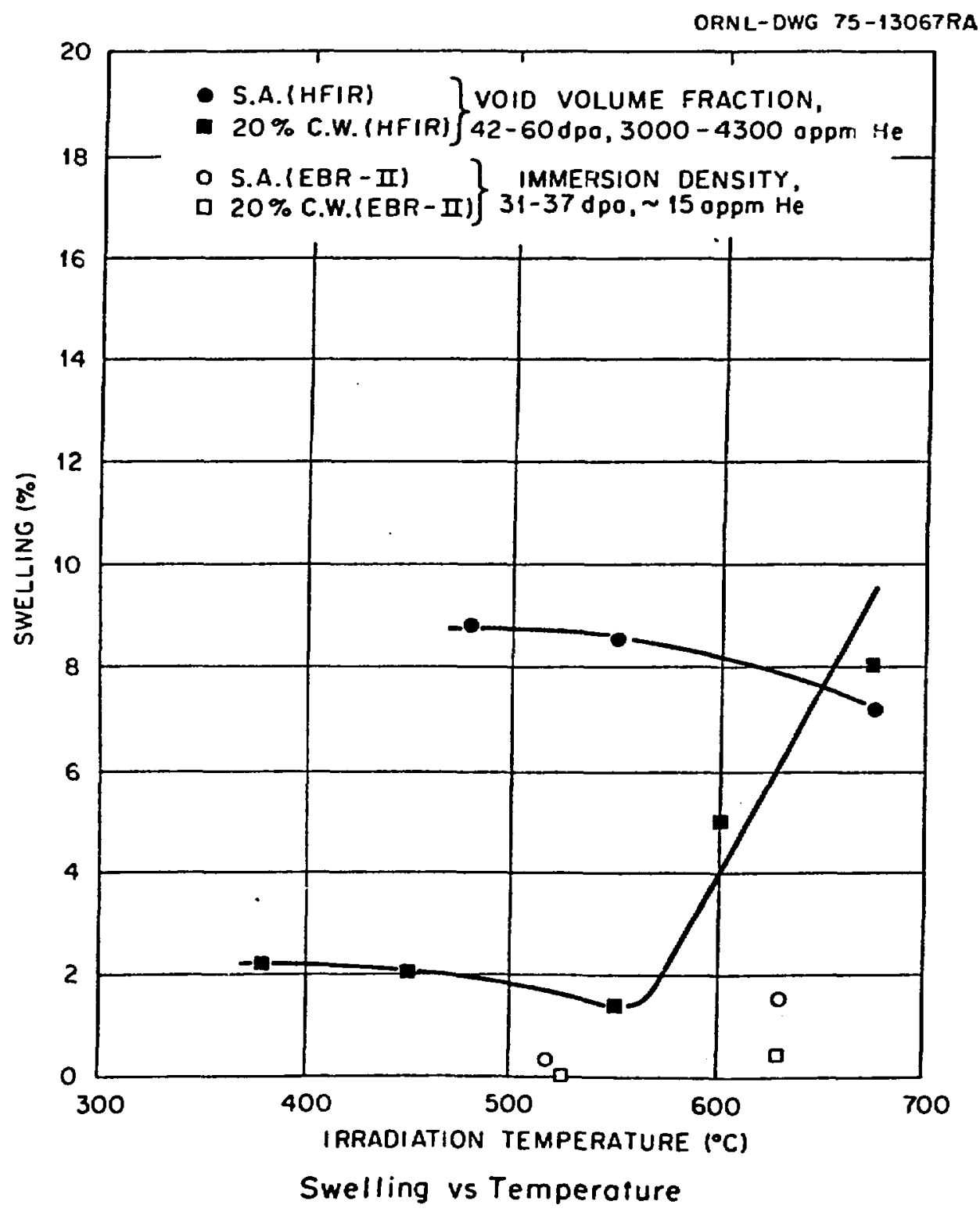

Fig. 8. A High Helium Content in 316 Sta inless Steel Causes a Hton Swelling Rate. 


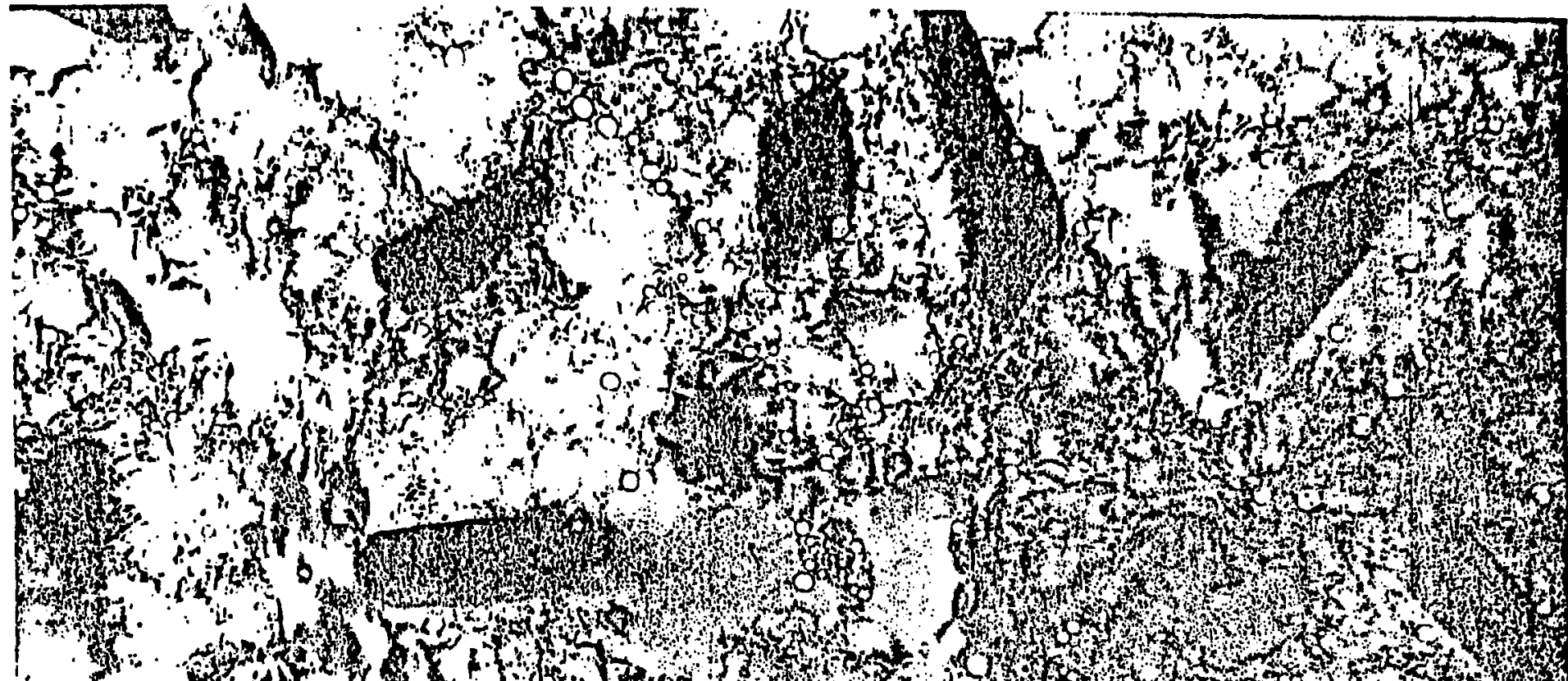

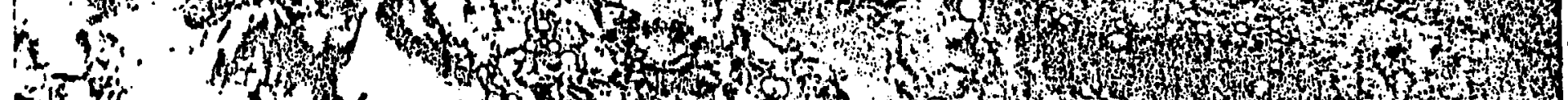

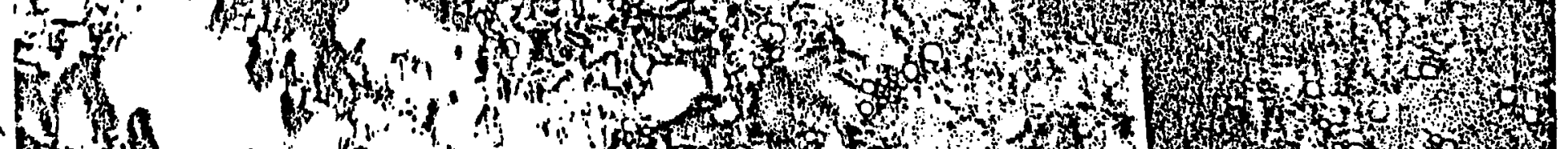
(1)

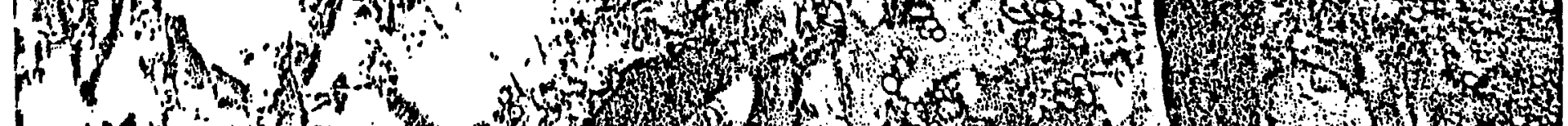
1.

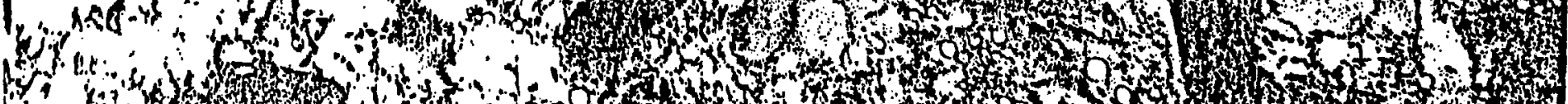
$\left.H_{i}, 4\right)$, (1)

Fig. 9. Solution-Annealed Type 316 Stainless Steel with $0.23 \mathrm{wt} \% \mathrm{Ti}$ after Irradiation in HFIR at $600^{\circ} \mathrm{C}$ to $30 \mathrm{dpa}$ and $1850 \mathrm{appm} \mathrm{He.}$ 
Fig. 10. Helium Trapping at a TiC Particle in Type 376 Stainless Steel.
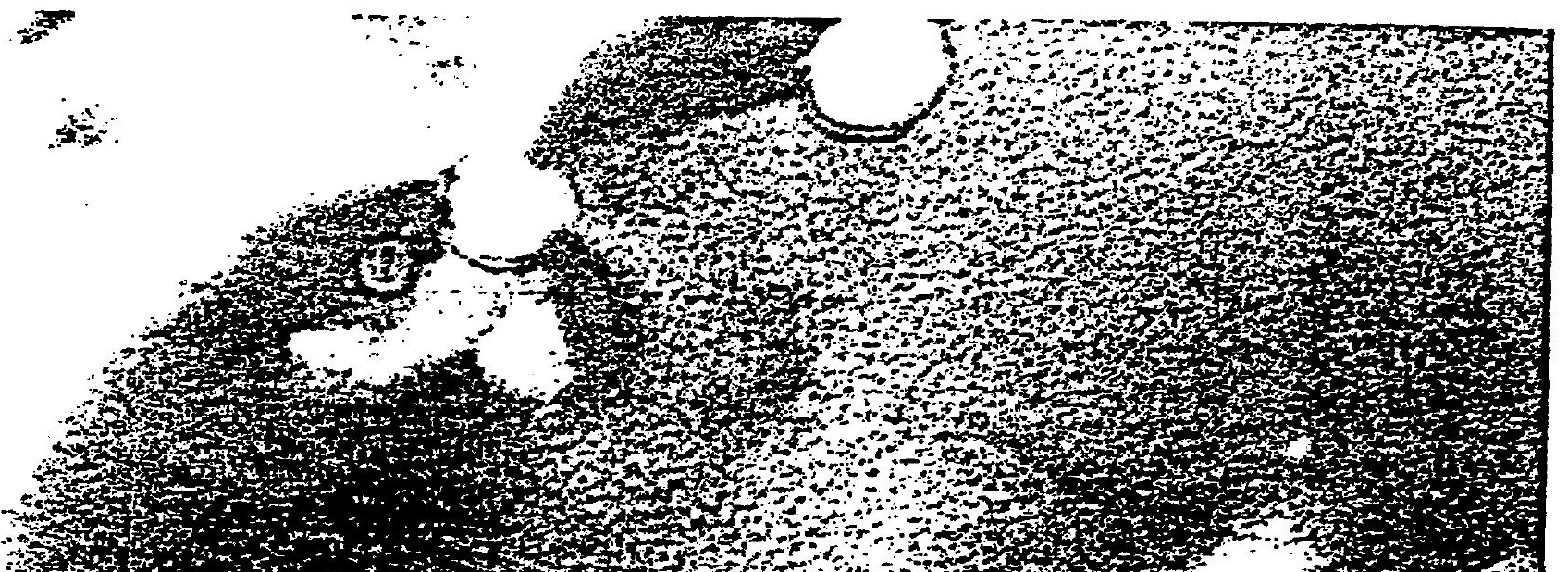

10.

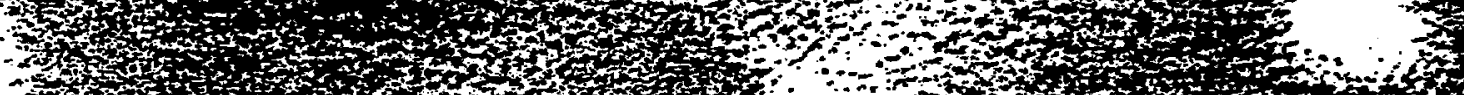

-

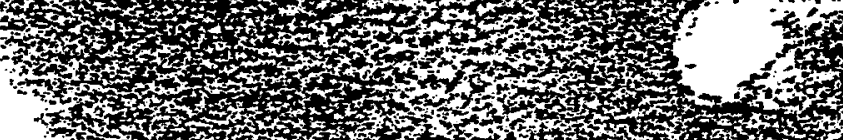

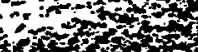

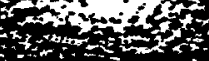

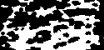

$=$

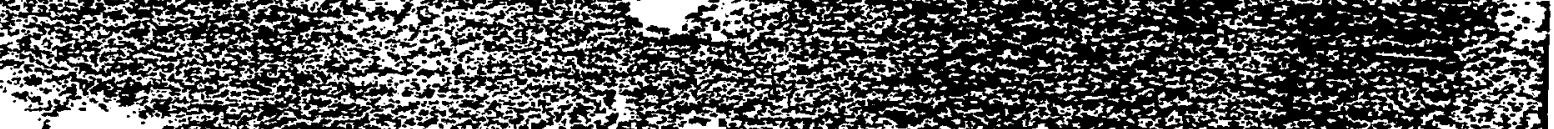

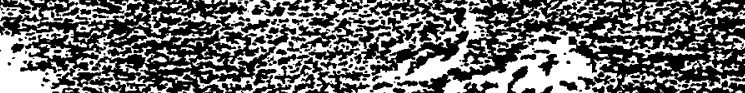

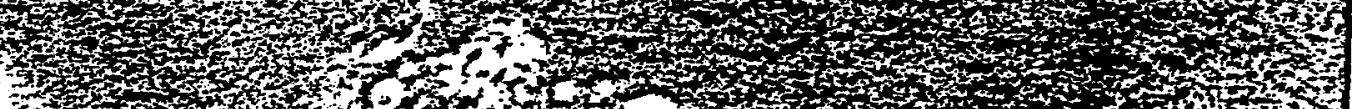

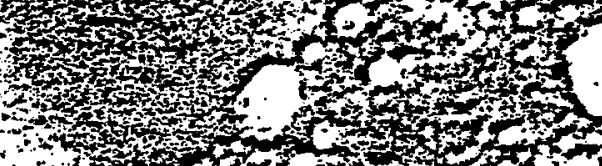

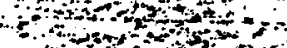

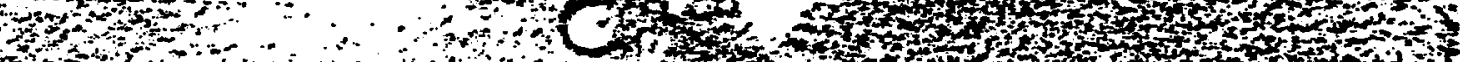

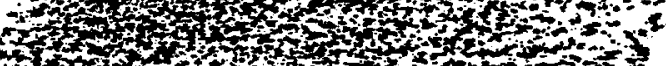

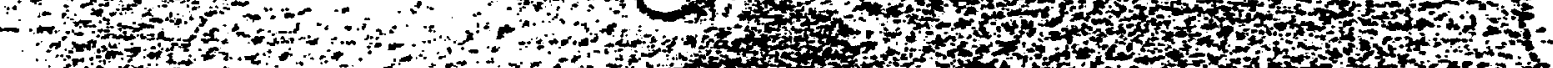

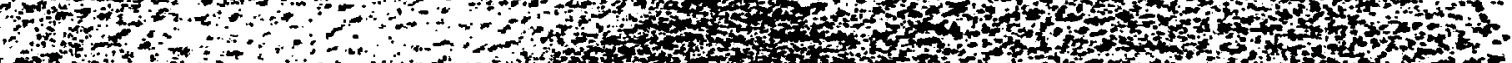

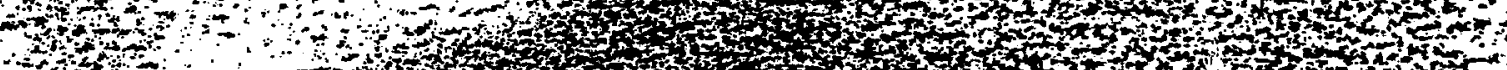

Fon

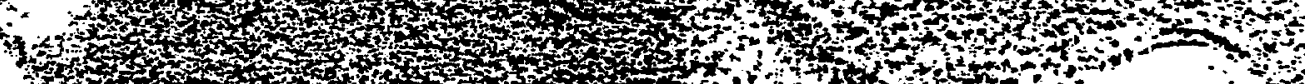

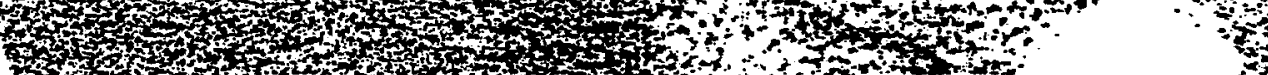

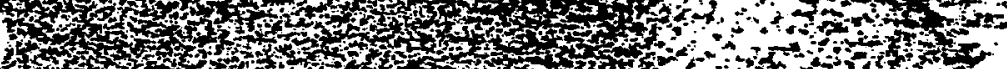

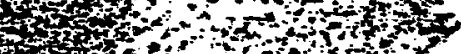

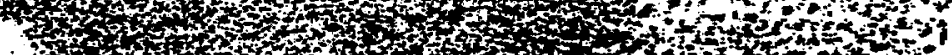

$=350$.

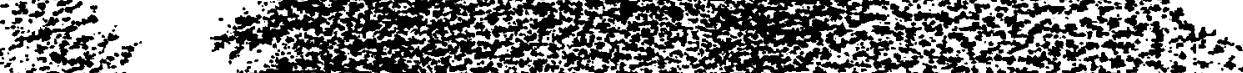

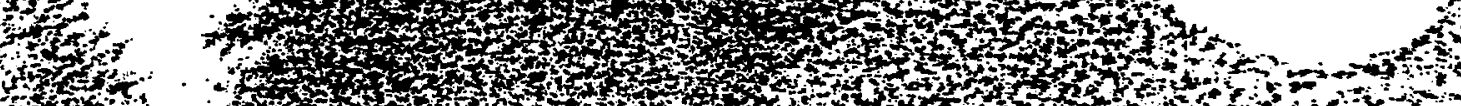

(1)

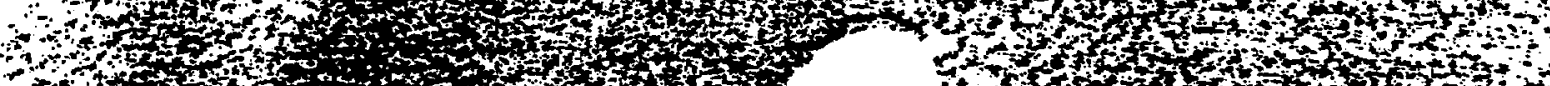

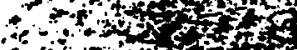

and

1.t.

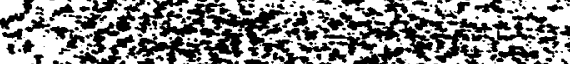

and

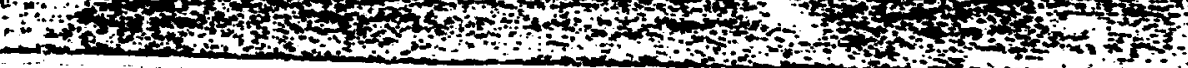

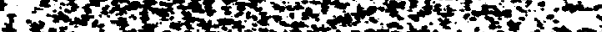

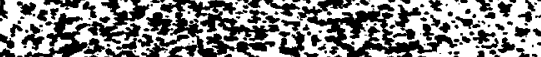

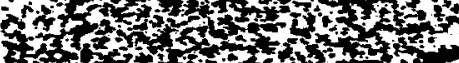


Ff. 11 . Amealed Type 376 Stainless Steel after Irradiation in HEIR at $600^{\circ} \mathrm{C}$ to 30 dpe and 1850 appan He.

$B-19172 \quad Y E-11481 \quad 3 X$

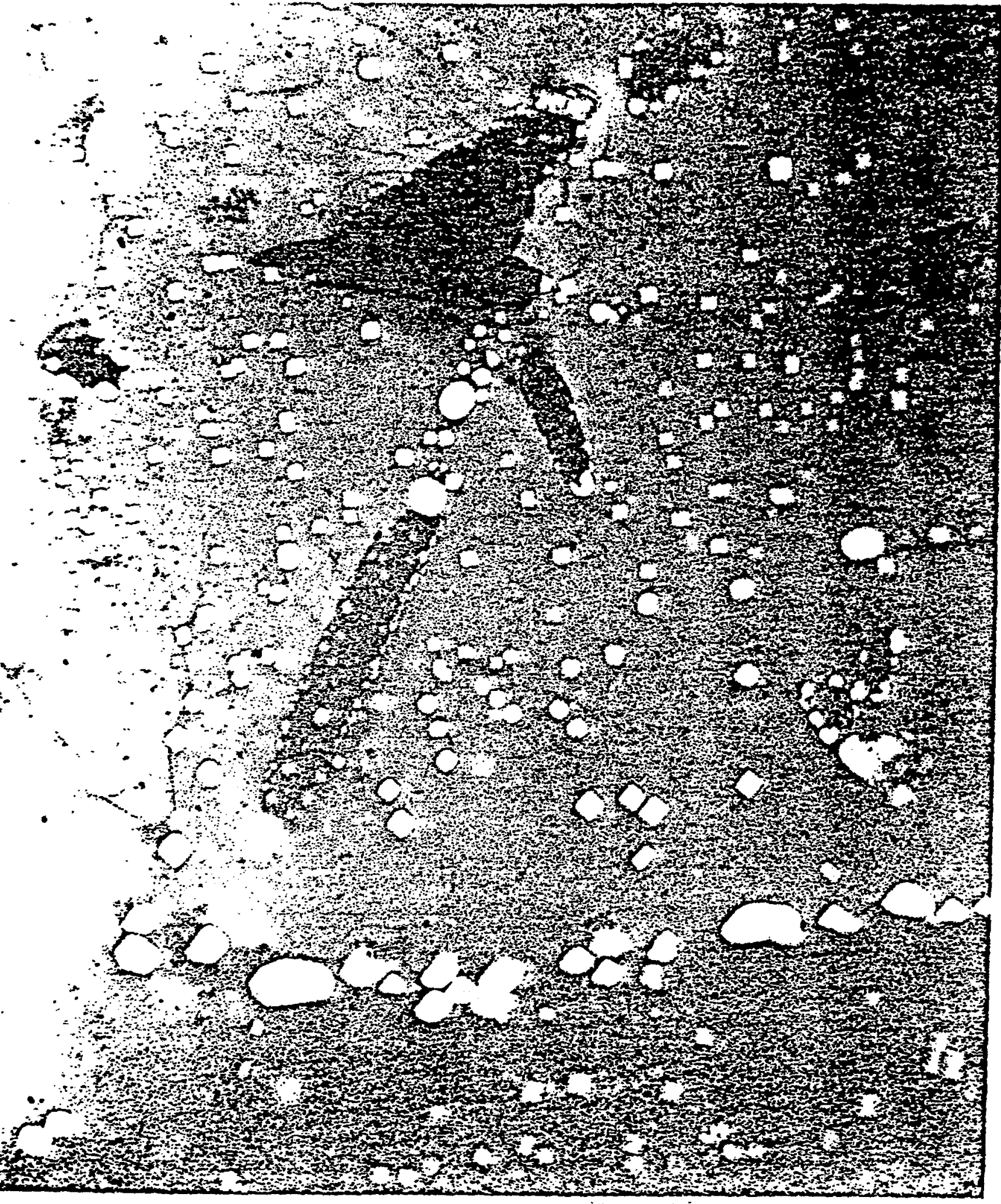

